\title{
Metabolic and Contractile Protein Expression in Developing Rat Diaphragm Muscle
}

\author{
A. M. Kelly, ${ }^{1}$ B. W. C. Rosser, ${ }^{4}$ R. Hoffman, ${ }^{1}$ R. A. Panettieri, ${ }^{3}$ S. Schiaffino, ${ }^{6}$ N. A. Rubinstein, ${ }^{2}$ and P. M. \\ Nemeth ${ }^{4,5}$ \\ Departments of 'Pathobiology, School of Veterinary Medicine, of ${ }^{2}$ Anatomy and of ${ }^{3}$ Medicine, School of Medicine,

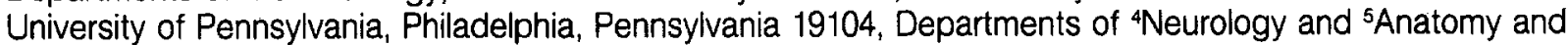 \\ Neurobiology, Washington University School of Medicine, St. Louis, Missouri 63110, and ${ }^{6}$ Institute of General Pathology, \\ University of Padua, 35100, Padua, Italy
}

Progressive changes in myosin isozyme expression and in energy-generating enzyme activities were followed in the diaphragm and, for comparison, in axial and appendicular muscles of rats from $18 \mathrm{~d}$ gestation to maturity. Native myosins were characterized by pyrophosphate gel electrophoresis. Myosin heavy-chain (MHC) isozymes were measured with ELISA using monoclonal antibodies and were localized by immunocytochemistry. RNA transcripts for the MHCs were demonstrated on Northern blots and by RNase protection assays. Quantitative activities of malate dehydrogenase (MDH), $\beta$-hydroxyacyl CoA dehydrogenase ( $\beta O A C), 1$-phosphofructokinase (PFK), lactate dehydrogenase (LDH), creatine kinase (CK), and adenylokinase (AK) were measured in muscle homogenates and in individual fibers by fluorometric pyridine nucleotide-dependent assays.

Compared to limb muscles, expression of neonatal myosin in the diaphragm is precocious. Neonatal MHC mRNA is prominent in the diaphragm at $19 \mathrm{~d}$ gestation, and neonatal myosin is the major MHC isoform present at birth. Slow and fast Ila MHCs are also present at birth. Transcripts for lla MHC are detectable in the diaphragm at $21 \mathrm{~d}$ gestation and are upregulated at birth. Comparable signal for lla MHC mRNA is not found in the gastrocnemius until $10 \mathrm{~d}$ postpartum. Adult fast IIb MHC mRNA was detected only as a faint signal at 30-40 $\mathrm{d}$ in the diaphragm and then disappeared. Results indicate that a separate phenotype, the IIx type, matures late in diaphragmatic development. The activities of enzymes representing all of the major energy pathways are higher in the fetal diaphragm than in the fetal hindlimb muscles. For example, $B O A C$ had sixfold higher activity in the diaphragm than in the extensor digitorum longus (EDL) muscle at birth. activity in the diaphragm than in the extensor digitorum longus (EDL) muscle at birth.

Received July 12, 1990; revised Nov. 21, 1990; accepted Nov. 28, 1990.

We wish to thank Dr. Frank Burns for a gift of the cDNA library for 19-d rat muscle, Dr. Robin Fitzsimmons for a gift of the NOQ7-5-4D antibody, Dr. Oliver Lowry for critical reading of the manuscript, Mrs. Zsuzzi Paltzman, Mrs. Rati Choksi, and Mr. John Leferovitch for their expert technical assistance, and Ms. Kathleen Haeber and Mrs. Patti Nacci for typing the manuscript. The research was supported by NIH Grants HL15835 to the Pennsylvania Muscle Institute and DK 38375 and by a grant from the Muscular Dystrophy Association of America.

Correspondence should be addressed to Dr. A. M. Kelly, School of Veterinary Medicine, University of Pennsylvania, Philadelphia, PA 19104.

Copyright (C) 1991 Society for Neuroscience 0270-6474/91/111231-12\$03.00/0
The results show that there is a temporal correlation between the metabolic capacity and the pattern of MHC expression in the developing diaphragm. In utero, this pattern of development anticipates the respiratory demands imposed on the diaphragm at birth.

The diaphragm is unique in that it is the only skeletal muscle that is essential for survival following the onset of aerobic respiration at birth. This must be anticipated in utero so that the contractile and metabolic machinery of the diaphragm are appropriately equipped to sustain these abruptly imposed demands. "Practice" respiratory movements initiated in utero undoubtedly play a role in preparing the muscle for this vital task (Dawes, 1984). At birth the rat diaphragm is capable of supporting a frequency of approximately 100 breaths per minute (Okubo and Mortola, 1988). The neonatal diaphragm also has a high resistance to fatigue; indeed, it is even higher than in the adult (Sieck and Blanco, 1987). Whether this is achieved through unusually high levels of oxidative enzymes is presently controversial (Keens et al., 1978; Maxwell et al., 1983; Smith et al., 1988).

Muscle-shortening velocities are largely determined by the ATPase activity of the myosin heavy-chain (MHC) isozymes expressed by myofibers. During muscle histogenesis, the heavy chains progress through a series of developmentally regulated transitions, and these have been extensively studied in limb muscle (Whalen et al., 1981; Gambke et al., 1983; Lyons et al., 1983; Periasamy et al., 1984; Mahdavi et al., 1987; Weydert et al., 1987; Russell et al., 1988). The functional significance of these switches, however, remains unclear because analyses of the $\mathrm{MHC}$ isozymes expressed early in differentiation, embryonic and neonatal $\mathrm{MHC}$, are presently incomplete. We have recently shown that enzyme levels in the oxidative and glycolytic pathways are low in all fibers of developing limb muscles at birth, suggesting they have only modest capacities to generate ATP. In view of this, we speculate that embryonic and neonatal MHCs, the predominant $\mathrm{MHC}$ isozymes expressed in the neonatal limb, are adapted to make economical use of constrained energy supplies (Nemeth et al., 1989).

Limb muscle development differs from that of the diaphragm in that the performance of ambulatory movements is gradually acquired after birth. In view of this distinction in neonatal demands, we anticipated that there should be distinct programs of contractile protein expression. We address this question in 
the present study by following the sequential expression of $\mathrm{MHC}$ isoforms and their mRNAs in the developing diaphragm, sternomastoideus, and hindlimb muscles beginning in utero. We also examine the relationship between the patterns of $\mathrm{MHC}$ expression and energy metabolism in the developing diaphragm to see if they are coordinated temporally and can be understood in the context of respiratory functional development. We show that the patterns of MHC switching and metabolic enzyme maturation in the developing diaphragm are precocious, and we suggest how this is uniquely designed to support sustained activity.

Preliminary results related to this project have been published previously (Rosser et al., 1988; Kelly et al., 1990).

\section{Materials and Methods}

Sprague-Dawley rats, including fetal rats with their time-mated pregnant mothers (Hilltop Laboratories, Philadelphia, PA) were killed in a $\mathrm{CO}_{2}$ chamber. Five to 10 animals were used for each perinatal time point; two animals were used at 4 weeks and at each subsequent time point. Muscle samples were taken from an equatorial band of the diaphragm, gastrocnemius, extensor digitorum longus (EDL), soleus, and sternomastoideus muscles; samples were quickly frozen in liquid nitrogen and stored at $-80^{\circ} \mathrm{C}$.

\section{Myosin heavy-chain isozymes}

Actomyosin was prepared from muscle samples for electrophoretic and ELISA studies as previously described (Narusawa et al., 1987). The native myosin isozymes of diaphragm and sternomastoideus muscles were separated by pyrophosphate gel electrophoresis according to the method of Hoh and Yeoh (1979), modified by Lyons et al. (1983), on $4.5 \%$ polyacrylamide slab gels using $5 \mu \mathrm{g}$ of actomyosin per lane.

Specific myosin isozymes were quantified in the diaphragm by ELISA, following the method outlined in the Bio-Rad Clone Selector instruction manual (Bio-Rad Labs, Richmond, CA). Three monoclonal antibodies were used: NOQ7-5-4D for slow MHC (Narusawa et al., 1987), SC-71 for Ila MHC (Schiaffino et al., 1989), and MY-32, which recognizes neonatal and all fast myosin heavy chains (Harris et al., 1989; Sigma Chemical Co., St. Louis, MO). One microgram of actomyosin was loaded into wells of microtiter plates, and antibodies were assayed in triplicate. In addition, frozen transverse sections of muscles were reacted with the same three antibodies following the procedures of Narusawa et al. (1987).

\section{mRNA of myosin heavy-chain isoforms}

Total cellular RNA was isolated from diaphragm and gastrocnemius muscles using standard procedures (Maniatis et al., 1982).

Oligonucleotide probes and Northern blots. Twenty-base-pair oligonucleotide probes were synthesized using published sequences unique to the $3^{\prime}$ untranslated region of the embryonic, neonatal, and IIb MHC genes (Nadal-Ginard et al., 1982). The complementary sequence for embryonic MHC was CCCTCACCAGGAGGACATGC (hybridization temperature, $61^{\circ} \mathrm{C}$ ) and for neonatal MHC was GCGGCCTCCTCAAGATGCGT (hybridization temperature, $59^{\circ} \mathrm{C}$ ). The complementary sequence for IIb MHC has been published (Gustafson et al., 1986). The oligonucleotide probes were end labeled with ${ }^{32} \mathrm{P}$-cytosine triphosphate (Maxam and Gilbert, 1980).

Ten micrograms of total RNA were size fractionated on 1\% agarose gels and transferred to GENE Screen (New England Nuclear, Boston, MA) for Northern blot hybridization with the labeled synthetic probes following the procedure of Maniatis et al. (1982).

$c D N A$ probe and $R$ Nase protection studies. A cDNA library made with mRNA isolated from 19-d-old rat muscle was constructed in the $\lambda \mathrm{gt} 11$ vector system (a gift from Dr. Frank Burns, Wistar Institute). The library was screened using the oligonucleotide probe specific for the IIb MHC untranslated region (see above), and a unique cDNA clone, pRMHC7, containing IIb MHC sequences, was identified using high-stringency hybridization and subcloned into Bluescript (Stratagene, LaJolla, CA). Double-stranded plasmid DNA was sequenced using the Sequenase DNA sequencing kit (U.S. Biochemical Corp., Cleveland, OH). Each nucleotide was sequenced at least twice. The homology was compared with known rat IIb MHC sequences (Nadal-Ginard et al., 1982) using the NMATPUs program from the PC Gene software package (Intelligenetics, Inc., Mountain View, CA). The RESTRI program (PC Gene, Intelligenetics, Inc.) was used to analyze the sequence for restriction enzyme cutting sites. This sequence has been submitted to EMBL gene bank.

The complementary RNA probe for IIb MHC was transcribed from an Hinfl fragment of pRMHC7 using T3 polymerase (Promega, Madison, WI) and $\alpha-{ }^{32} \mathrm{P}$-cytosine triphosphate (Amersham Corp., Arlington Heights, IL) as the labeled nucleotide. The total probe length was 261 nucleotides, of which 188 nucleotides correspond to part of the $3^{\prime}$ coding region and the entire 3' untranslated region of the rat IIb MHC gene, and 73 nucleotides correspond to vector sequence (Hoffman, 1990). Within the sequences corresponding to the $3^{\prime}$ coding region, 67 nucleotides are homologous to IIa MHC sequences, and 53 nucleotides are homologous to neonatal MHC sequences. Probe from pRMHC7 was therefore able to hybridize with three different messages in protection assays, and the different sizes of the three protected fragments were resolved on $6 \%$ acrylamidc denaturing gels. The RNase protection assays were performed according to the method outlined by Ausubel et al. (1986). Ten micrograms of total RNA were used for each hybridization.

\section{Enzymatic activities}

Whole-muscle homogenates. Six enzymes were chosen to represent the major energy-generating pathways: $\beta$-hydroxyacyl $\mathrm{CoA}$ dehydrogenase $(\beta O A C)$ for fatty acid oxidation, malate dehydrogenase (MDH) for the citric acid cycle, 1-phosphofructokinase (PFK) and lactate dehydrogenase (LDH) for glycolysis, and creatine kinase (CK) and adenylokinase (AK) for high-energy phosphate metabolism. These enzymes were selected either because of their rate-limiting roles in their respective pathways or because previous work demonstrated their high susceptibility to modulation under experimental protocols (Chi et al., 1986). The homogenate preparation from frozen muscle samples and the fluorometric enzyme assays have been previously described (Chi et al., 1983). Protein content was determined with BCA-1 kit (Sigma Chemical Co., St. Louis, MO), and activities were expressed as $\mathrm{mol} / \mathrm{kg}$ protein $/ \mathrm{hr}$ at $21^{\circ} \mathrm{C}$.

Single-fiber enzyme analysis. Muscle fibers from young perinatal rats cannot be histochemically typed by standard myosin ATPase staining procedures, and, therefore, individual fibers were randomly selected for biochemical analysis. Procedures for tissue handling and measuring enzyme activities in fragments (1-20 ng) of single fibers have been previously described (Nemeth et al., 1986). Assay protocols for MDH activity are from Hintz et al. (1980), and those for AK, LDH, and $\beta \mathrm{OAC}$ activities are from Lowry et al. (1978). Assays included an appropriate standard to calculate the enzyme activities in $\mathrm{mol} / \mathrm{kg}$ dry weight $/ \mathrm{hr}$ at $21^{\circ} \mathrm{C}$. For comparison with homogenate values, $85 \%$ of muscle dry weight was assumed to be protein (Dickerson and Widdowson, 1960).

For adult muscles, advantage was taken of the ability to analyze specific enzyme activities in individual fibers typed histochemically. Transverse sections of muscles were stained by myosin ATPase reactivity after preincubation at $\mathrm{pH} 4.5$, and muscle fibers were judged as types I, IIa, or IIb by dark, light, and intermediate staining, respectively (Brooke and Kaiser, 1970; modified by Nemeth and Turk, 1984). Alternate transverse sections were lyophilized for biochemical analyses. Fragments of individual fibers, classified into fiber types using histochemically stained sections, were dissected from the unstained lyophilized sections (Nemeth et al., 1986) and subjected to enzyme assays as described above for perinatal muscle.

\section{Results}

\section{MHC isozymes}

Native myosin isozymes. The pattern of myosin isozyme switching in the developing diaphragm is shown in Figure 1. In the 18-d fetus, the isozyme composition of the diaphragm comprised five bands. There were 2 pronounced bands ( $\mathrm{f} 4$ and $\mathrm{f} 3$ ), which have been correlated in previous studies with the expression of embryonic myosin (Whalen et al., 1981; Lyons et al., 1983). Also present at $18 \mathrm{~d}$, migrating with successively faster mobilities, were isozymes $\mathrm{f} 2$ and $\mathrm{f} 1$. Together with overlap from $\mathrm{f}$, these are interpreted as isozymes of neonatal myosin (Whalen et al., 1981; Lyons et al., 1983).

The identity of the slowest migrating band $\left(f_{*}\right)$ in the $18-d$ 


\section{Diaphragm}

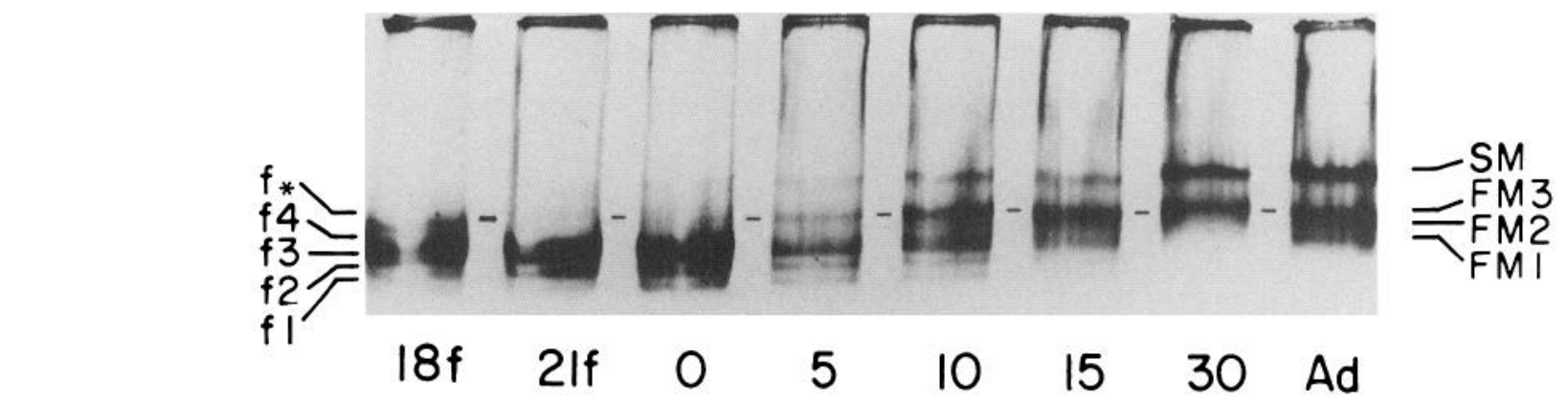

\section{Sternomastoideus}

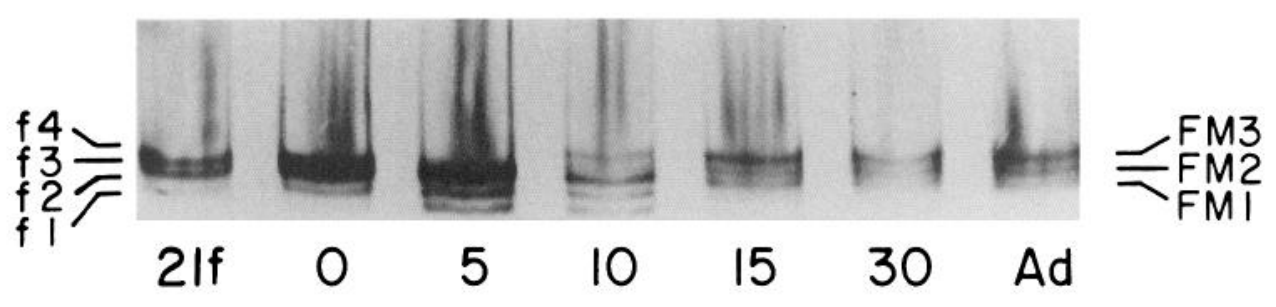

\section{Age in Days}

Figure 1. Pyrophosphate gels showing the isozyme composition of native myosin isozymes from diaphragm and sternomastoideus muscles at successive stages of development. Designations are $f(l-4)$ for embryonic and neonatal myosin isozymes, $F M(l-3)$ for adult fast myosin, and $S M$ for isozymes of slow myosins, according to the nomenclature of Hoh and Yeoh (1979). The expression of neonatal $(f l-3)$ and adult $(A d)$ myosin isozyme FM3 occurs earlier in the diaphragm than in the rostral sternomastoideus muscle. The identity of the slowest migrating band ( $\left.f_{*}\right)$ is uncertain.

fetal diaphragm is uncertain; it has a mobility similar but not identical to that of the adult fast isozyme FM3. Isozymes of neonatal myosin were the major isoforms present in the diaphragm at birth; they persisted until $15 \mathrm{~d}$ postpartum and were not detected after this time. Isozymes of neonatal myosin are reportedly not detected until $21 \mathrm{~d}$ gestation on nondenaturing gels of limb muscle, and they are eliminated by $15 \mathrm{~d}$ of age (Whalen et al., 1981; Lyons et al., 1983). In the present study, Figure 1 shows that, in the sternomastoideus, the full complement of neonatal isozymes including $\mathrm{fl}$ (the homodimer of $\mathrm{LC}_{3}$ ) is only faintly detectable at birth but is clearly present by $5 \mathrm{~d}$. Neonatal myosin isozymes are not present after $15 \mathrm{~d}$ in the sternomastoideus. These results show that accumulation of neonatal myosin isozymes in the developing diaphragm precedes that in other muscles, but the coincidence of elimination at 15 d suggests the involvement of similar inhibitory controls. Thyroid hormone is known to play a role in the process of inhibition in limb muscles (Gambke et al., 1983; Russell et al., 1988).

Slow and adult fast myosins were faintly visible in the diaphragm at 21 d gestation; both were more evident at birth and progressively increased to maturity.

Specific MHC isozymes. The relative proportions of slow and adult fast MHCs were measured at successive stages of diaphragmatic development using ELISA and monoclonal antibodies specific for slow (NOQ7-5-4D), for IIa (SC-71), and for all fast MHCs (MY-32; Fig. 2). Relative proportions of slow MHC were low at birth and increased approximately threefold by $20 \mathrm{~d}$. Thereafter, proportions of slow MHC declined by approximately $20 \%$ to maturity. Fast IIa MHC was also present in small amounts at birth and increased 2.5 -fold by $20 \mathrm{~d}$. Pro-

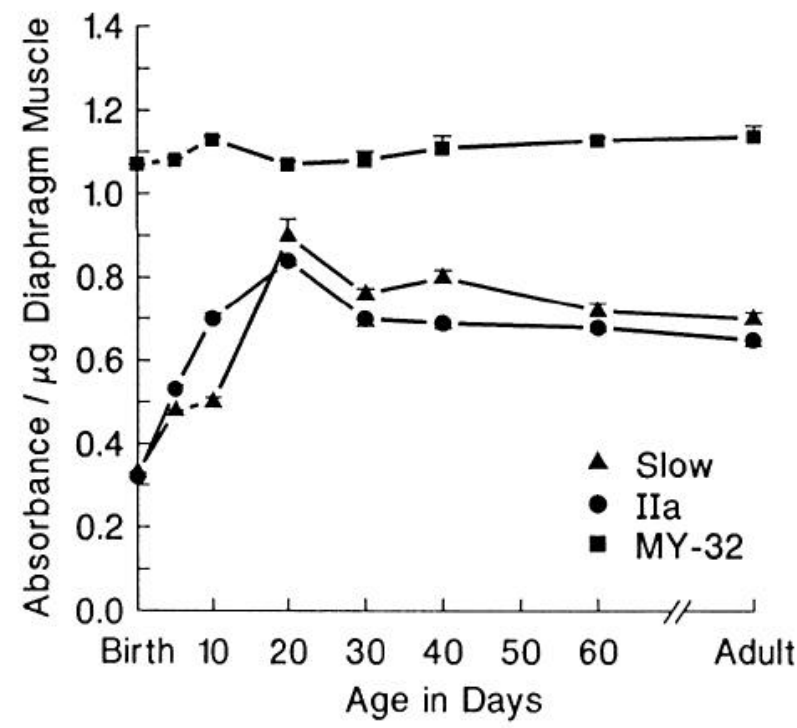

Figure 2. Relative proportions of MHC isozymes in the developing diaphragm obtained from ELISAs with monoclonal antibodies NOQ75-4D to slow and SC-71 to adult IIa MHCs. The MY-32 antibody cross-reacts with neonatal, IIa, IIb, and IIx myosin isoforms. Slow and IIa myosins reached peak levels by $20 \mathrm{~d}$ postpartum and decline to adulthood, whereas the MY-32 antibody reaction did not decline after $20 \mathrm{~d}$. Units are absorbance \pm SE of triplicate determinations at $405 \mathrm{~nm}$ of $p$-nitrophenyl in the alkaline phosphatase reaction per microgram of actomyosin. 

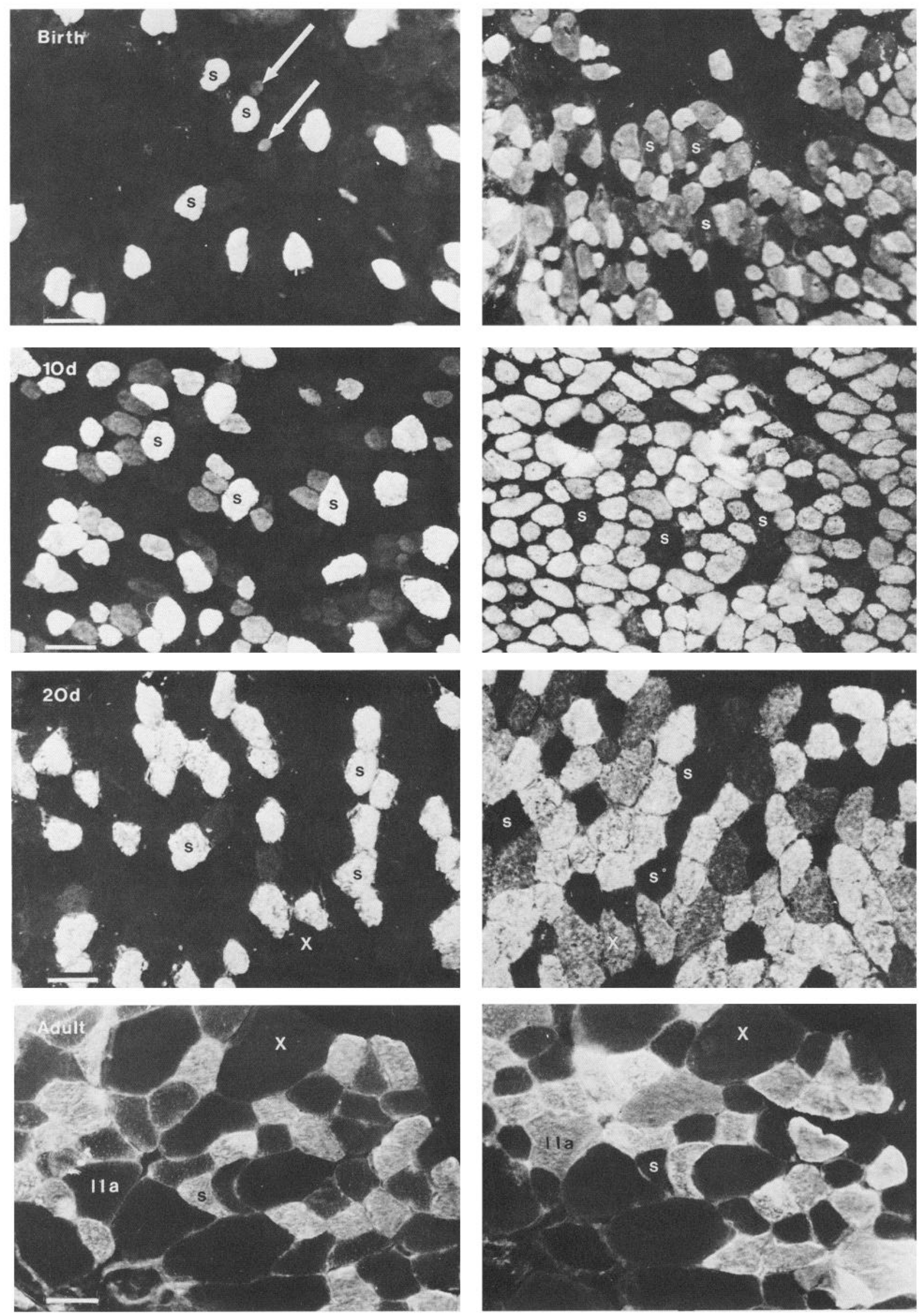
portions of IIa MHC decreased thereafter in parallel with slow MHC.

Binding of the monoclonal antibody MY-32, which recognizes fast MHCs (neonatal, IIa, IIb, and IIx) but not slow MHC, did not decrease after $20 \mathrm{~d}$ (Fig. 2). Because proportions of IIa $\mathrm{MHC}$ are coincidently decreased and neonatal $\mathrm{MHC}$ had been eliminated (Fig. 1), the data suggest that another fast isozyme, either IIb and/or IIx MHC, was increased during the period after $20 \mathrm{~d}$.

Immunocytochemistry provided additional information about the emergence of specialization in the developing diaphragm (Fig. 3). At birth, approximately $12 \%(n=1100$ total fibers counted in 2 animals; SD, $\pm 1 \%$ ) of the fibers stained intensely for slow myosin. The slow population increased to $25 \%(n=$ $700 ; \mathrm{SD}, \pm 3 \%)$ at $10 \mathrm{~d}$ and to $36 \%(n=600 ; \mathrm{SD}, \pm 3 \%)$ at 20 d. This approximated the adult slow population of $34 \%(n=$ $800 ; \mathrm{SD}, \pm 2 \%$ ).

The increase in the slow fiber population results from the maturation of secondary generation cells. We interpret the relatively large, widely segregated fibers staining intensely for slow $\mathrm{MHC}$ at birth (Fig. 3, $\mathrm{S}$ in top panels), as primary generation slow fibers (Rubinstein and Kelly, 1981). Some smaller cells, juxtaposed to primary fibers, stained weakly for slow MHC at birth (Fig. 3, arrows) and with greater intensity at $10 \mathrm{~d}$. These were interpreted as secondary generation fibers that were switching to the slow phenotype. As a result, slow fibers are clustered into groups at $20 \mathrm{~d}$ and in the adult.

The IIa MHC antibody reacted with variable intensity to a significant number of fibers at birth and to a greater number of fibers at $10 \mathrm{~d}$. There was greater variability of staining with the IIa MHC antibody at $20 \mathrm{~d}$, and in the adult approximately $35 \%$ of fibers stained with this antibody. Many fibers, including all large fibers (Fig. 3, X), do not stain with IIa antibody in the adult. However, large fibers in the adult diaphragm stain well with monoclonal MY-32, indicating that these cells accumulate a fast MHC (Fig. 4). Although these large fibers stained as IIb with the myosin ATPase histochemical reaction (not shown), we will show that IIb MHC mRNA is expressed at very low levels in the diaphragm (see below). In view of the work of Schiaffino et al. (1986, 1989), Bär and Pette (1989), and Termin et al. (1989), this leads to the conclusion that large fibers of the diaphragm accumulate IIx MHC. The present results also indicate that this phenotype matures late in development.

\section{$M H C M R N A$}

The pattern of MHC expression was further investigated using highly specific oligonucleotide probes complementary to the $3^{\prime}$ untranslated region of embryonic and neonatal MHC mRNAs.

Transcripts for embryonic MHC were detected on Northern blots of the fetal diaphragm at $19 \mathrm{~d}$ gestation; the signal was stronger at $21 \mathrm{~d}$ and was not detected after birth (Fig. 5). The signal for embryonic MHC mRNA in the gastrocnemius was faint at $19 \mathrm{~d}$ gestation and progressively increased in intensity

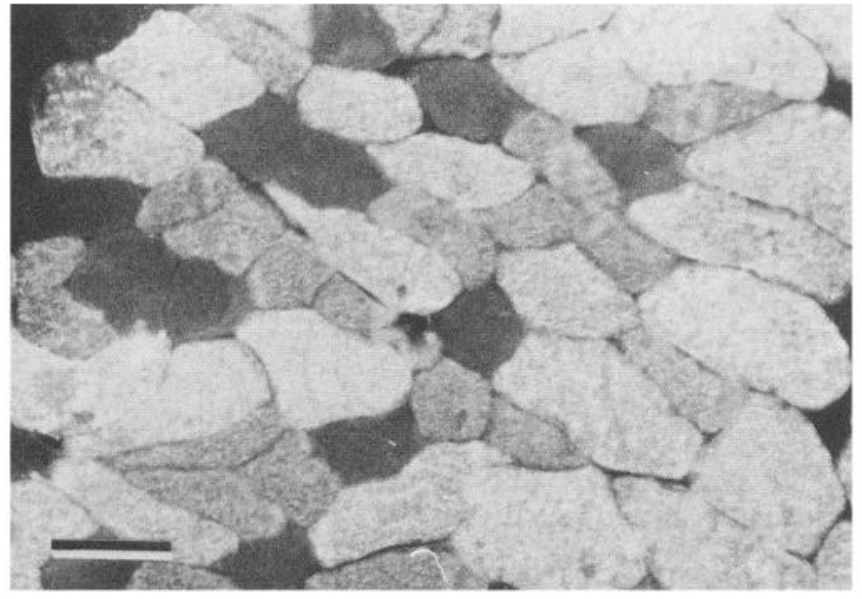

Figure 4. Section of adult diaphragm muscle stained with MY-32. Large fibers stain with this antibody, which recognizes all fast MHCs. Scale bar, $35 \mu \mathrm{m}$.

by birth and $5 \mathrm{~d}$ postpartum (Fig. 5). Because the loadings of total RNA were the same for both muscles, it is unclear from this analysis why the relative abundance of embryonic MHC mRNA differs in the diaphragm compared to the gastrocnemius. The results, however, do show that the pattern of embryonic $\mathrm{MHC}$ expression in the diaphragm is distinct from that of the gastrocnemius.

Expression of neonatal MHC mRNA was also tissue specific. The signal for neonatal MHC mRNA was perceptible on Northern blots from the diaphragm at $19 \mathrm{~d}$ in utero; it was strong at $21 \mathrm{~d}$ gestation and then progressively declined in intensity by $10 \mathrm{~d}$ postpartum, after which time it was no longer detected. In the gastrocnemius, the signal was not perceptible until $21 \mathrm{~d}$ gestation, was strong at birth and at 5 and $10 \mathrm{~d}$, and was then abruptly eliminated so that neonatal MHC transcripts were not detectable at $15 \mathrm{~d}$. This pattern of expression of neonatal MHC transcripts correlates with the analyses of neonatal myosin isozyme accumulation shown in Figure 1.

The appearance of transcripts for the $3^{\prime}$ untranslated region of IIa MHC was also investigated using several oligonucleotide probes, but these gave equivocal results. To overcome this, a specific RNase protection assay was used with a 261-nucleotide cDNA probe that included the entire $3^{\prime}$ untranslated region of IIb MHC and extended 181 nucleotides into the coding region (see Materials and Methods). Because of homologies in the coding region, this probe partially protected $3^{\prime}$ sequences of IIa and neonatal myosins. The 3 different messages (neonatal, IIa, and IIb MHC) were size fractionated on polyacrylamide gels.

The upper panels in Figure 6 show that neonatal MHC mRNA was expressed in the diaphragm by $19 \mathrm{~d}$ gestation in greater amounts than in the gastrocnemius. This is consistent with the results obtained on the less sensitive Northern blots (Fig. 5). IIa

\footnotetext{
Figure 3. Immunocytochemical staining for slow and IIa MHC at selected times of diaphragmatic development: left panels, slow antibody; right panels, IIa antibody. Both antibodies showed a progressive increase in number of reactive fibers up to $20 \mathrm{~d}$. After this time, fibers staining for IIa MHC declined in incidence. Fibers staining exclusively for slow MHC at birth $(S)$ were interpreted as primary generation slow fibers. Some secondary generation cells stained weakly for slow at this stage (arrows). At $10 \mathrm{~d}$, with the exception of primary slow fibers $(S)$ most fibers stained with the IIa antibody. Many large fibers in the adult muscle did not react with either the slow or IIa antibody $(X)$. Scale bars: Birth, $12 \mu \mathrm{m} ; 10 d, 20 \mu \mathrm{m}$; $20 \mathrm{~d}, 25 \mu \mathrm{m} ;$ Adult, $35 \mu \mathrm{m}$.
} 


\section{Gastrocnemius}

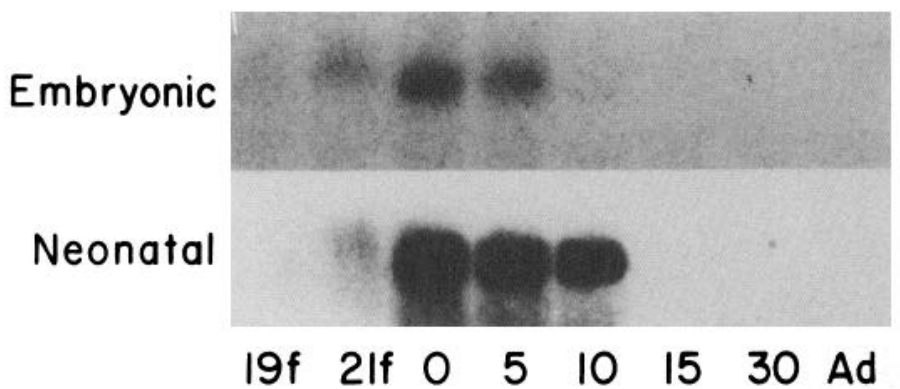

\section{Diaphragm}

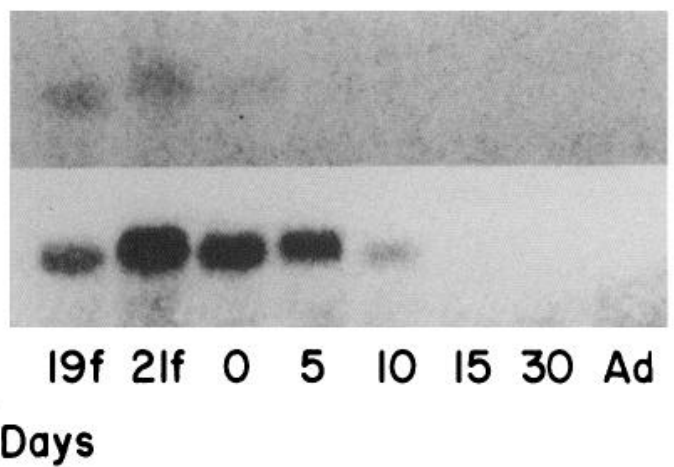

Figure 5. Northern blots showing expression of embryonic and neonatal MHC mRNAs at successive stages of fetal and postnatal development in the diaphragm and gastrocnemius muscles. Transcripts for neonatal MHC are present in the diaphragm at $19 \mathrm{~d}$ gestation $(19 \mathrm{f})$. Signal is increased in strength at $21 \mathrm{~d}$ gestation $(21 f)$ and then slowly declines to $10 \mathrm{~d}$ postpartum. In the gastrocnemius, by contrast, transcripts for neonatal MHC abruptly increase between $21 \mathrm{~d}$ gestation and birth and are eliminated equally abruptly after $10 \mathrm{~d}$.

Figure 6 . RNase protection assays with the probe $\mathrm{pRMHC7}$. This probe gives full-length protection to $188 \mathrm{nu}-$ cleotides of $3^{\prime}$ translated region and the entire $3^{\prime}$ untranslated region of the IIb MHC gene. Within the coding sequences, 67 nucleotides are homologous with II MHC sequences, and 53 nucleotides are homologous with neonatal MHC sequences. The three protected fragments are differentiated by size on acrylamide gels and shown at successive stages of perinatal (upper panels) and postnatal (lower panels) development of the gastrocnemius and diaphragm muscles. Total RNA from the adult tensor fasciae latae (TFL), a fast IIb muscle, and from the liver were used as positive and negative controls, respectively. All loading concentrations were the same; $P b$, probe. In the upper panels, partial protection of neonatal MHC mRNA sequences is evident in the diaphragm at $19 \mathrm{~d}$ gestation $(19 f)$, and is enhanced at $21 \mathrm{~d}$ in utero (21f). By contrast, the signal for neonatal MHC mRNA in the gastrocnemius was weak at 19 and $21 \mathrm{~d}$ gestation and enhanced at birth. Partial protection of IIa transcripts is evident in the diaphragm at $21 \mathrm{~d}$ gestation (asterisks) and progressively increases to maturity. The signal for IIa MHC transcripts in the gastrocnemius is not well defined until $10 \mathrm{~d}$ postpartum. In the lower panels, there was a strong signal for IIb MHC in the gastrocnemius at $10 \mathrm{~d}$ after birth, and this was amplified with further development. In contrast, there were only traces of IIb MHC mRNA in the diaphragm at 30 and $40 \mathrm{~d}$, and they were not detected in the adult.
Gastrocnemius

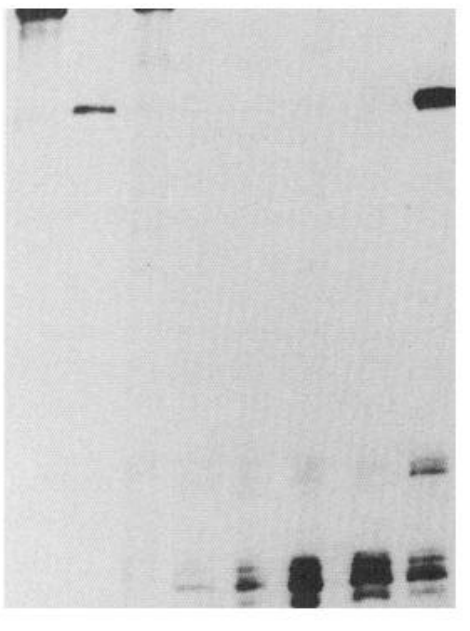

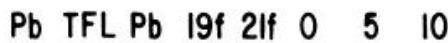

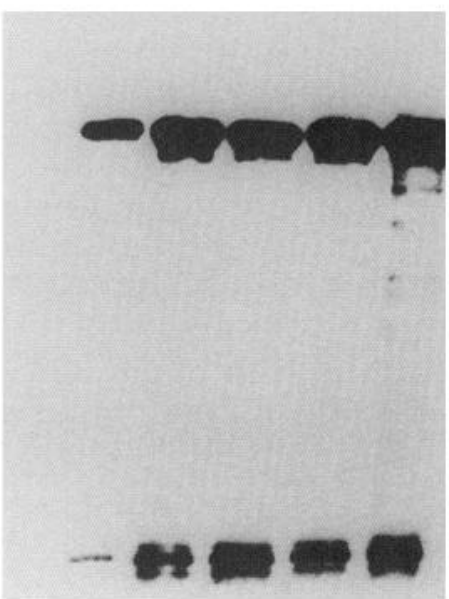

$\begin{array}{llllll}5 & 10 & 20 & 30 & 40 & \text { Ad }\end{array}$
Diaphragm
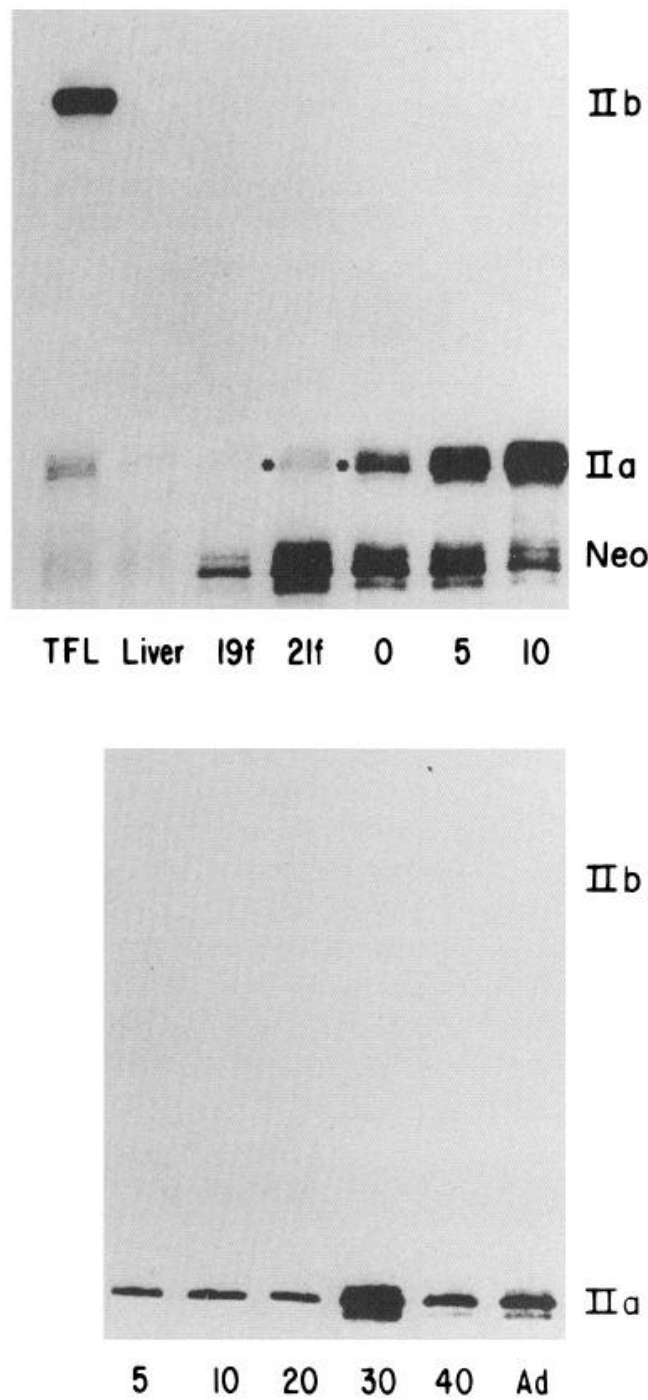

Age in Days 

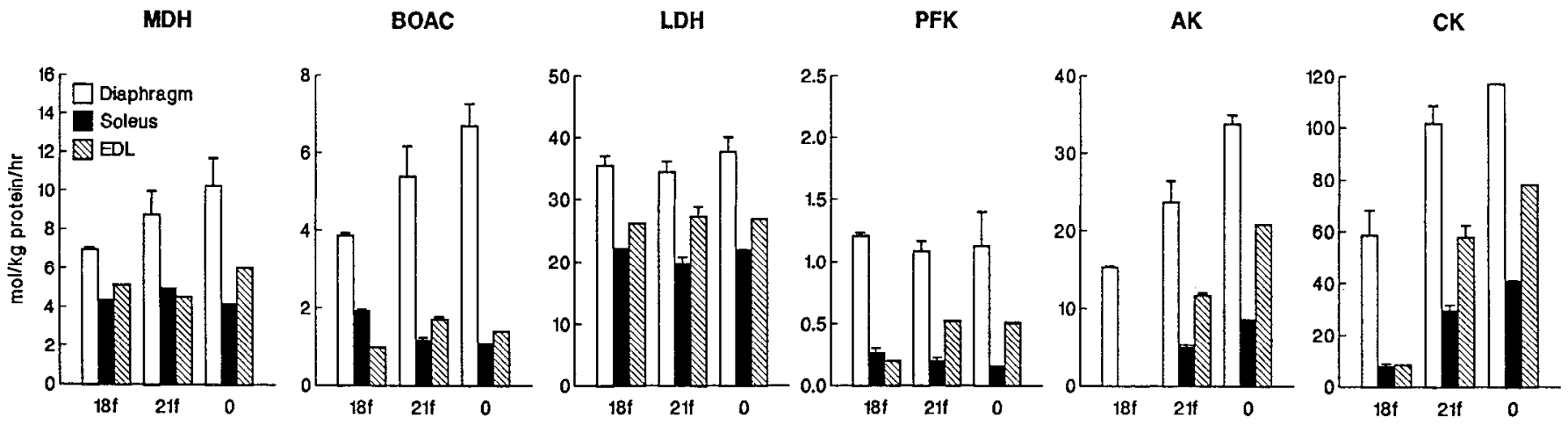

Figure 7. Enzyme activities in whole-muscle homogenates during perinatal growth. Activities are the means $\pm \mathrm{SE}$ from at least five animals. All enzymes had higher activities in diaphragm than in hindlimb muscles.

MHC mRNA was present at $21 \mathrm{~d}$ gestation in the diaphragm (Fig. 6, asterisks), and the signal progressively increased in strength thereafter. By contrast, there was only a faint signal for IIa MHC mRNA in the gastrocnemius between $21 \mathrm{~d}$ gestation and $10 \mathrm{~d}$ postpartum (Fig. 6, upper panels). After this time, IIa MHC mRNA in the developing gastrocnemius progressively increased in abundance (Fig. 6, lower panels).

The RNase protection assays also showed a marked difference in the relative abundance of IIb MHC mRNA. There was a strong signal for full-length protection of IIb MHC mRNA in the gastrocnemius from $10 \mathrm{~d}$ to maturity (Fig. 6, upper and lower panels). In the diaphragm, IIb MHC mRNA was not expressed until $30-40 \mathrm{~d}$, and then only a weak signal was obtained (Fig. 6, lower panels). This weak signal was not maintained in the adult. IIb MHC is therefore not a meaningful constituent of contractile machinery in the adult diaphragm, and these findings support the interpretation that the large fibers of the adult diaphragm express IIx MHC as described by Schiaffino et al. (1986, 1989), Bär and Pette (1989), and Termin et al. (1989).

\section{Metabolic capacity}

Enzyme activities were measured in whole-muscle homogenates of the developing diaphragm and were compared to those in the soleus, a prospective slow oxidative muscle, and in the EDL, a prospective fast glycolytic muscle.

The activities of all six enzymes selected to represent energy metabolism (see Materials and Methods) were much higher in the diaphragm than in either of the hindlimb muscles in the fetus and neonate (Fig. 7). Thereafter, divergent pathways of maturation emerged for the three muscles as they independently achieved their specific adult metabolic profiles (Fig. 8).

Oxidative enzymes. Throughout development, oxidative capacity was higher in the diaphragm than in the soleus or the EDL muscles. This was evident at $18 \mathrm{~d}$ gestation when average $\mathrm{MDH}$ activity was 1.6-fold and 1.4-fold higher, and $\beta \mathrm{OAC}$ activity was 1.3 -fold and 4.3 -fold higher, in the diaphragm than in the soleus and EDL muscles, respectively (Fig. 7). These activities rose sharply in the diaphragm as the animal approached parturition. By the time of birth, MDH activity was 2.0 -fold higher, and $\beta \mathrm{OAC}$ activity was 5.6 -fold higher, than the average values for the hindlimb muscles.

Activities of these oxidative enzymes continued to increase in the diaphragm, with two- to threefold increases between birth and 6 weeks (Fig. 8). At the same time, oxidative enzyme activity increased in the soleus and EDL muscles but was always lower than in the diaphragm. After 6 weeks, oxidative enzyme levels fell in the diaphragm by approximately $30 \%$ to maturity.

Glycolytic enzymes. The capacity for glycolytic metabolism was greater in the fetal diaphragm, with LDH 1.5 -fold higher and PFK 6.0-fold higher, than the average values for the fetal hindlimb muscles (Fig. 7). In the diaphragm, these enzymes changed little between birth and approximately 6 weeks. Glycolytic activity then rose abruptly in the diaphragm and was doubled by maturity (Fig. 8, LDH and PFK). In contrast, glycolytic enzyme activity in the EDL muscle rose immediately after birth so that levels surpassed those of the diaphragm by about 1 week.

Enzymes of high-energy phosphate metabolism. AK and CK activities were also higher in the diaphragm than in hindlimb muscles at birth, with 4.0-fold and 1.6-fold higher AK and 2.8fold and 1.5-fold higher CK activities in diaphragm compared to soleus and EDL, respectively (Fig. 7). These enzymes then gradually rose to peak values by about 6 weeks in the diaphragm, as did the glycolytic enzymes, but unlike the oxidative enzymes, there was little or no reduction in activity to reach adult levels (Fig. 8).

The enzyme profile that emerged in the adult diaphragm was high in oxidative capacity, even higher than that of the soleus muscle. Glycolytic and high-energy phosphate capacity was intermediate between the slow soleus and fast EDL.

Single-fiber metabolic capacity. In order to follow the timing of cellular metabolism in particular fiber types, individual fibers of developing diaphragm and EDL muscles were assayed in the same animal for selected enzymes (Fig. 9). By $5 \mathrm{~d}$, diaphragm fibers had LDH, AK, and MDH activities in or near the range of adult type I and IIa fibers. In contrast, the EDL fibers at $5 \mathrm{~d}$ had AK and LDH activities in or near the range of adult type I and IIa fibers, but MDH was far below the adult levels. Thus, oxidative metabolism appears to be advanced in the diaphragm compared to the EDL muscle.

Further temporal changes in the metabolic profile of diaphragm fibers are shown in Figure 10. The 5-d enzymatic profile (Fig. 9, diaphragm AK vs. LDH) remained essentially unchanged at 20 and $40 \mathrm{~d}$. The metabolic profile of IIx fibers did not emerge until after this time. These enzyme results correspond to the delayed maturation of the large fibers that are neither type I nor IIa by immunocytochemistry, as shown in Figure 3.

The adult metabolic phenotype of diaphragm muscle fibers can be compared to that of the EDL muscle in Figure 10. Adult 

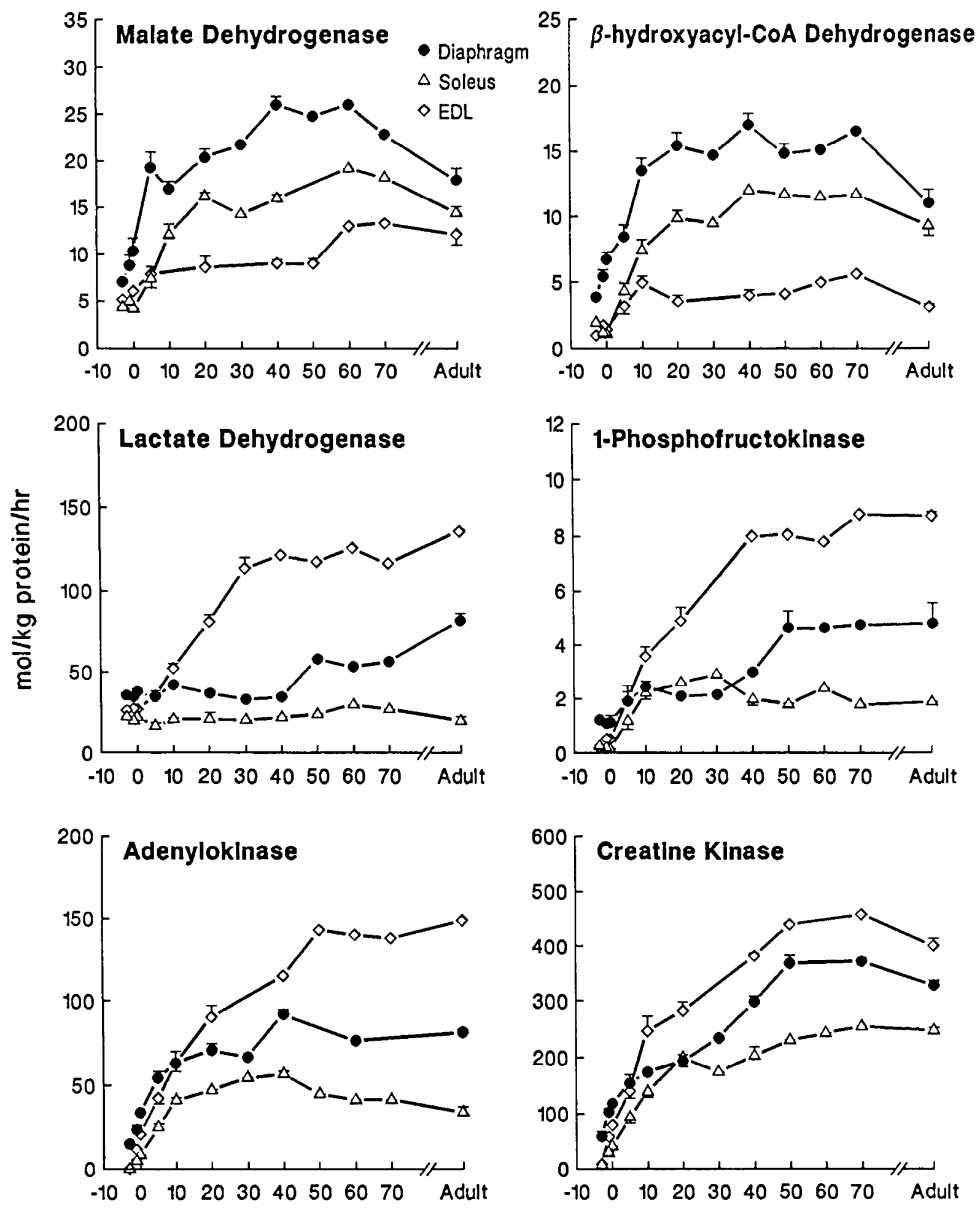

Age in Days

Fïgure 8. Enzyme activities in whole-muscle homogenates at successive stages of development compared to the adult. Activities are in mol/kg protcin/hr and are expressed as means \pm SE from 2-10 animals. Oxidative enzymes advanced to their peak levels earlier in the diaphragm than in hindlimb muscles.

fibers of histochemical types I and IIa each had similar activities of $\mathrm{MDH}, \mathrm{LDH}$, and $\mathrm{AK}$ in the two muscles. However, the enzyme profiles of a population of fibers, histochemically identified in previous literature as type IIb, differed in these muscles:
AK was similar, but $\mathrm{LDH}$ was lower (on average, 95 vs. 128 $\mathrm{mol} / \mathrm{kg}$ dry weight $/ \mathrm{hr}$ ) and MDH was far higher (15 vs. $8 \mathrm{~mol} /$ $\mathrm{kg}$ dry weight/hr), in the diaphragm than in the EDL. These enzyme differences can be correlated with the MHC analyses 

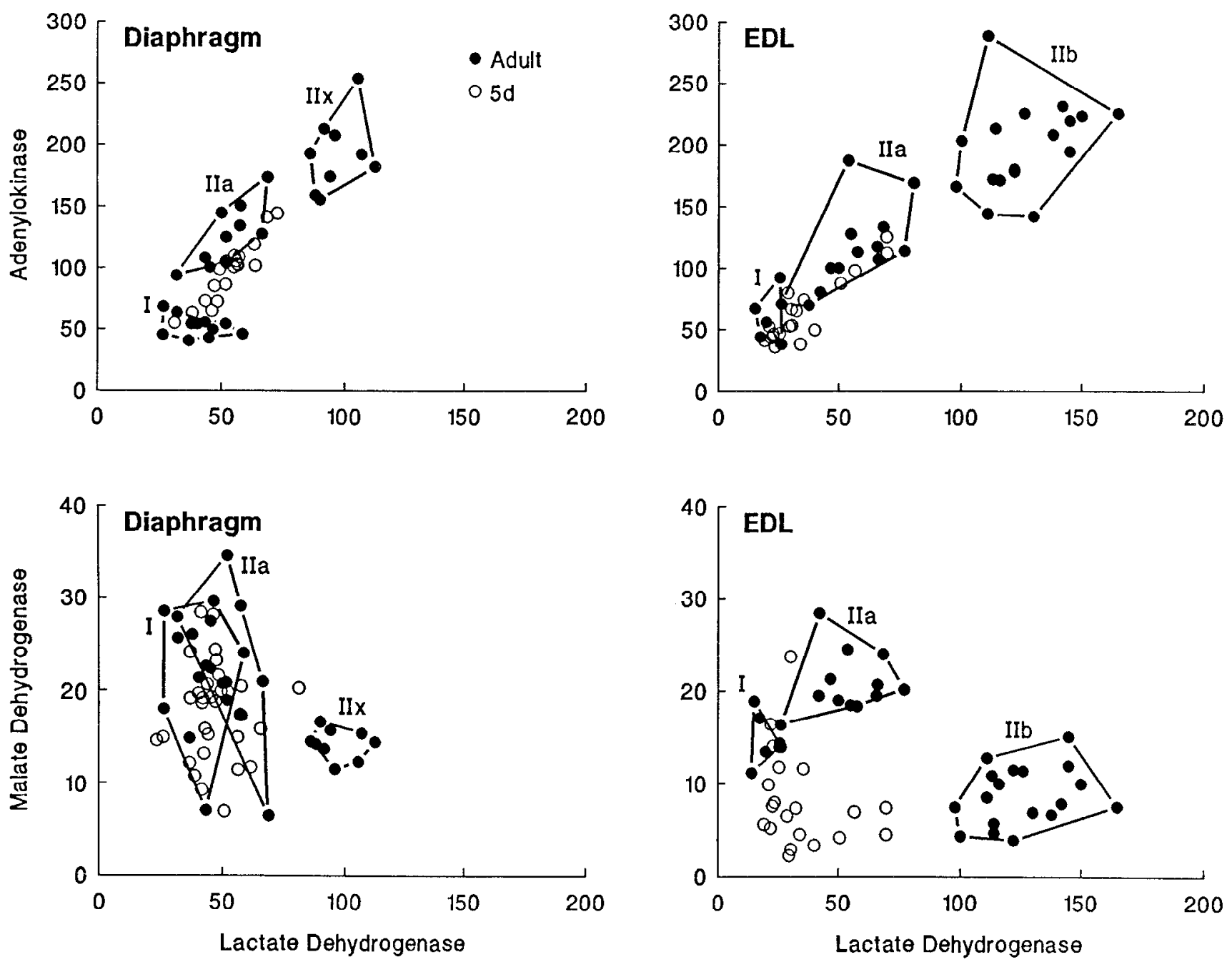

Figure 9. Enzyme activities at $5 \mathrm{~d}$ and adulthood in individual fibers of rat diaphragm and EDL muscle. Each point represents two enzyme activities plotted against each other (top, AK vs. LDH; bottom, MDH vs. LDH) on a single fiber, expressed as mol $/ \mathrm{kg} \mathrm{dry} \mathrm{weight} / \mathrm{hr}$. Adult EDL fibers are identified as types I, Ila, or IIb by myosin ATPase staining reactivity (shown by enclosed polygons). The histochemically defined IIb fiber population in the diaphragm contained IIx myosin and is designated IIX. All fibers in the diaphragm had enzymes in the range of adult type I or IIa at $5 \mathrm{~d}$. In contrast, the EDL muscle had MDH values far below the adult type I or IIa levels at $5 \mathrm{~d}$. The IIx fibers were not metabolically differentiated at $5 \mathrm{~d}$.

and indicate that fibers designated as type IIx in the diaphragm are metabolically distinct from type IIb fibers in muscles of the hindlimb.

\section{Discussion}

The present study follows the transitions in MHC expression and metabolic activity in the diaphragm muscle with the goal of understanding how these programs are coordinated during the development of respiratory function.

\section{Intrauterine preparation}

By a variety of techniques, we show that elimination of embryonic MHC and initiation of neonatal and adult fast IIa MHC expression in the developing diaphragm is tissue specific and precedes that of other skeletal muscles. This is demonstrated by electrophoresis of native myosins (Fig. 1) and is consistent with the previous studies of d'Albis et al. (1989). Analyses of the expression of neonatal and IIa MHC mRNA confirm the precocious nature of muscle development in the diaphragm (Figs.
$5,6)$. In addition, we show that MHCs replace one another in a gradual way during development of the diaphragm, and that there is little discontinuity of this process during the precipitous shift from intra- to extrauterine life. This was an unexpected finding that may indicate that diaphragmatic development is designed to minimize adjustments in protein synthesis at parturition and to provide a broad interval of safety in the event of premature delivery.

The present results also show that the advanced programs of MHC expression in the diaphragm are temporally correlated with shifts in the capacity for the major energy pathways. Enzymes representing oxidative, glycolytic, and high-energy phosphate metabolism are all higher in the fetal diaphragm than in fetal hindlimb muscles, indicating that the metabolic capacity of the diaphragm is not suddenly acquired at birth but is gradually installed before the muscle is involved in supporting gas exchange. The results show that advances in maturation of the diaphragm are global, and they are consistent with our premise that there is coordinate regulation of specific energy require- 


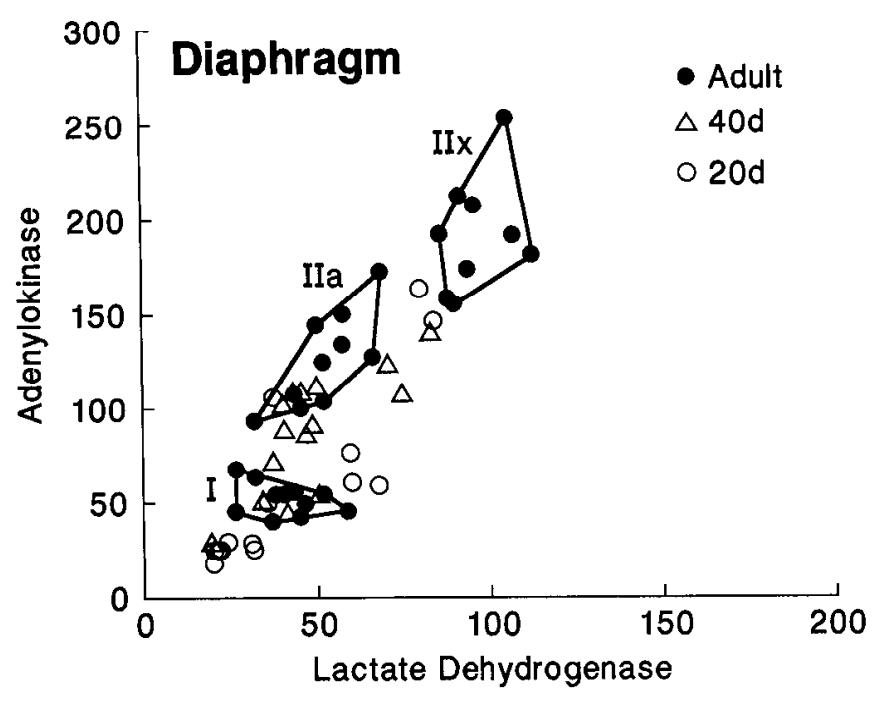

Figure 10. Enzyme activities in individual fibers at progressive stages of diaphragmatic development; values and fiber designations are as in Figure 9. While fibers having the metabolic profile of type I and IIa were present at $20 \mathrm{~d}$, few fibers having the metabolic profile of the IIx phenotype were evident at 20 or $40 \mathrm{~d}$.

ments with each of the developmental myosin isoforms so that fatigue does not compromise essential muscle function (Nemeth et al., 1989).

Furthermore, there is early metabolic specialization with respect to substrate utilization. For example, the activity of $\beta \mathrm{OAC}$, an enzyme for fatty acid oxidation, is three times higher at 18 $\mathrm{d}$ gestation and six times higher at birth in the diaphragm than in the hindlimb muscles. This intrauterine adaptation anticipates the neonatal period of physiological hyperlipidemia that accompanies suckling and a high-fat milk diet (Page et al., 1971). $\beta$-Oxidation provides highly efficient metabolism with respect to energy yield per mole of substrate and is a typical pathway of adult type I and IIa fibers. Early activation of this pathway probably also has long-term effects on metabolism by altering the absolute levels of $\beta$-oxidative enzymes in the diaphragm and contributing to the fatigue-resistant properties of the muscle throughout development.

Little is known about the factors that regulate the advanced pattern of $\mathrm{MHC}$ expression in the developing diaphragm. One possible explanation is that the primordium of the more rostral diaphragm is modeled before that of the hindlimb musculature. However, we show that the emergence of neonatal myosin isozymes in the sternomastoideus, a muscle of the neck, succeeds that of the diaphragm (Fig. 1) and closcly rescmbles that of hindlimb muscles (Whalen et al., 1981; d'Albis et al., 1989). It is also unclear whether the advanced development of the diaphragm is due to precocious neuromuscular function because contractile activities in limb and respiratory muscles are reported to begin at the same time in the human fetus (deVries et al., 1982).

\section{Extrauterine adaptations}

Respiratory frequencies in the newborn rat approximate 100 breaths per minute (Okubo and Mortola, 1988). After birth, the metabolic rate rises, and the increased $\mathrm{CO}_{2}$ production in turn drives up respiratory rates to a peak of nearly 200 breaths per minute at $20 \mathrm{~d}$. Respiratory rates then slowly decline to the adult resting ratc of approximatcly 110 breaths per minute (Okubo and Mortola, 1988). The rapid respiratory rates of the infant rat are rarely accompanied by elevations in tidal volume. For example, tidal volumes change little in response to hypoxia in the rat prior to $10 \mathrm{~d}$ postpartum (Okubo and Mortola, 1988). This is probably an adaptation to the instability of the chest wall in the neonate due to lack of mineralization of the ribs. Rapid shallow respirations appear to be more efficient than deep breaths at this time because they are less likely to distort a compliant chest wall (Mortola, 1984; Bryan and Gaultier, 1985).

To accommodate these demands, the diaphragm expresses neonatal $\mathrm{MHC}$ as the major isozyme present at birth (Fig. 1). Over the next $20 \mathrm{~d}$, neonatal myosin is progressively eliminated (Figs. 1, 5, 6; LaFramboise et al., 1990) and replaced by IIa $\mathrm{MHC}$. Because fibers containing neonatal $\mathrm{MHC}$ appear to have a lower shortening velocity than IIa fibers (Reiser et al., 1985, 1988), the progressive transition can be correlated with the rising metabolic rates and increasing respiratory frequencies of the growing rat. Increased expression of IIa MHC is also accompanied by high AK activity (Fig. 7), an enzyme that is correlated with high speed of contraction in mature muscle (Hamm et al., 1988). In addition, work by Reiser et al. (1988) shows that, in limb muscles, specific tension increases postnatally concomitant with the loss of neonatal MHC. Accumulation of neonatal MHC in the diaphragm at birth may therefore be matched with the early constraints of a compliant chest wall.

Type IIa fibers have high energy efficiency, so precocious expression of IIa MHC by the diaphragm (Fig. 6) may be understood as an adaptation for sustaining early respiratory demands. In view of the high resistance to fatigue by the neonatal diaphragm (Sieck and Blanco, 1987), it seems likely that fibers containing neonatal $\mathrm{MHC}$ are at least as well adapted for this function. As noted previously, IIa fibers, and presumably fibers containing neonatal MHC, make extensive use of $\beta$-oxidation (Figs. 7,8 ). This is coupled with an oxidative potential that is significantly higher than in limb muscles at comparable, early periods of development (Fig. 8; Smith et al., 1988). These are pathways that afford significant advantages for maintaining early diaphragmatic work. However, the metabolic capacity of fibers in the diaphragm at birth is significantly lower than in the adult (Fig. 8). This appears to be coupled with the lower shortening velocities of neonatal MHC and probably with lower energy costs per unit of force production. The rapid elevation of oxidative and high-energy phosphate metabolism in the diaphragm after birth therefore appears to be temporally correlated with elevations of IIa MHC accumulation and increased velocities of shortening.

\section{Adolescence to maturity}

There is a decline in respiratory frequencies after 3 weeks of age associated with a decrease in metabolic rate (Okubo and Mortola, 1988). We show that the neonatal diaphragm exhibits its highest concentration of IIa MHC at about 3 weeks after birth, accompanied by peak oxidative capacity. Subsequently, the relative proportions of IIa myosins and the oxidative enzyme activities decline, whereas glycolytic enzyme activitics morc than double by maturity. In this final phase of differentiation of the diaphragm, a new phenotype matures that provides greater force production (see below) at the expense of increased glycolytic metabolism.

Maturation of this fiber type coincides with hypertrophy of a select population of fast fibers (Figs. 3, 4). Histochemically, these 
fibers stain like IIb fibers (not shown) and react with an antibody that recognizes all fast MHCs in rats (Fig. 3) but not with an antibody to IIa MHC (Fig. 4). In previous literature, these fibers have been interpreted as type IIb (Maltin et al., 1985). However, we found that there is an insignificant signal with a specific probe for the IIb MHC mRNA in both the developing and the mature diaphragm (Fig. 6), and we have obtained similar results on Northern blots using an oligonucleotide probe complementary to the 3' untranslated region of IIb MHC mRNA (Kelly et al., 1990). The present results are consistent with previous protein analyses (Schiaffino et al., 1989; Termin et al., 1990) and are interpreted to indicate the maturation of IIx fibers, a phenotype that has been recently described by Schiaffino et al. $(1986,1989)$ and has been termed IId by Bär and Pette (1989) and Termin et al. (1989). Iype IIx fibers account for approximately 35\% of the total population in the mature rat diaphragm (Schiaffino et al., 1989).

Large IIx fibers make use of the high power output supported by glycolysis (Fig. 9) and are associated with a $V_{\max }$ that is similar to that of IIb fibers (Schiaffino et al., 1989). Consistent with this are AK levels similar to those of IIb fibers (Fig. 8). The unusually high oxidative potential of IIx fibers (Fig. 9) would, however, predict an enhanced resistance to fatigue compared to IIb fibers. Thus, the adult diaphragm possesses a fiber type, IIx, with forcegenerating capacity on the same order as IIb fibers but with unusually high energy efficiency characterized by higher oxidative potential than typical IIb fibers. We show that the IIx phenotype matures late in development (Figs. 3, 8, 9). This follows mineralization of the ribs and stabilization of the chest wall so that the growing animal acquires the facility for generating greater intrathoracic pressures appropriate for efficiently elevating tidal volumes.

Differentiation of IIx fibers increases the diversity of phenotypes in the diaphragm and probably permits greater selectivity of motor control for a wide range of physical activities. In the neonatal rat, when most fibers express neonatal, slow, or IIa MHC and there is extensive polyneural innervation (Rosenthal and Taraskevich, 1977), we speculate that a majority of fibers are recruited during each inspiratory cycle. Increasing strength of the developing diaphragm probably permits selective ordering of recruitment and progressive muscle specialization. Slow motor units, activated early in the inspiratory cycle (Iscoe et al., 1976), are the first to expand (Figs. 2, 3). This involves expression of slow MHC by secondary generation cells (Fig. 3). Later, large IIx fibers mature to augment the range of forces generated by the diaphragm. These large fibers may not be activated during quiet respiration but are supplementally recruited for deep inspiration in the adult (Sieck, 1988; Sieck and Fournier, 1989).

\section{References}

Ausubel FM, Brent R, Kingston RE, Moore D, Seidman JG, Smith J, Struhl K, eds (1986) Current protocols in molecular biology, Sec 4.7.1. New York: Wiley.

Bär A, Pette D (1989) Three fast myosin heavy chains in adult rat skeletal muscle. FEBS Lett 235:153-155.

Brooke MS, Kaiser KK (1970) Three myosin adenosine triphosphatase systems: the nature of their $\mathrm{pH}$ lability and sulfhydryl dependence. $\mathbf{J}$ Histochem Cytochem 18:670-672.

Bryan AC, Gaultier C (1985) Chest wall mechanics in the newborn. In: Lung biology in health and disease (Lenfant C, ed), pp 871-888. New York: Marcel Dekker.

Chi MM-Y, Hintz CS, Coyle EF, Martin w.H, Ivy JL, Nemeth PM, Holloszy JO, Lowry OH (1983) Effects of detraining on enzymes of energy metabolism in individual human muscle fibers. Am J Physiol 244:C276-C287.

Chi MM-Y, Hintz CS, Hendricksson J, Salmons S, Hellendahl RP, Park JL, Nemeth PM, Lowry OH (1986) Chronic stimulation of mammalian muscle: enzyme changes in individual fibers. Am J Physiol 251:C633-C642.

d'Albis A, Couteaux R, Janmot C, Rolet A (1989) Specific programs of myosin expression in postnatal development of rat muscle. Eur $\mathrm{J}$ Biochem 183:583-590.

Dawes GS (1984) The central control of fetal breathing and skeletal muscle movements. J Physiol (Lond) 356:1-18.

deVries JIP, Visser GH, Prechtl HFR (1982) The emergence of fetal behaviour. I. Qualitative aspects. Early Hum Dev 7:301-322.

Dickerson JWT, Widdowson EM (1960) Chemical changes in skeletal muscle during development. Biochem J 74:247-257.

Gambke B, Lyons G, Haselgrove J, Kelly AM, Rubinstein NA (1983) Thyroid and neural control of myosin transitions during development of rat fast and slow muscles. FEBS Lett 156:335-339.

Gustafson TA, Markham BE, Klorkin E (1986) Effects of thyroid hormone on alpha-actin and myosin heavy chain gene expression in cardiac and skeletal muscles of the rat: measurement of mRNA content using synthetic oligonucleotide probes. Circ Res 59:194-201.

Hamm TM, Nemeth PM, Solanki L, Gordor DA, Reinking RM, Stuart DG (1988) Association between biochemical and physiological properties in single motor units. Muscle Nerve 11:245-254.

Harris AJ, Fitzsimons RB, McFwan JC (1989) Neural control of the sequence of expression of myosin heavy chain isoforms in fetal mammalian muscles. Development 107:751-770.

Hintz CS, Lowry CV, Kaiser KK, McKee D, Lowry OH (1980) Enzyme levels in individual rat muscle fibers. Am J Physiol 239:C58C65.

Hoffman R (1990) Differential expression of myosin heavy chain genes in fast and slow muscles of the developing rat hindlimb in vivo and in vitro. $\mathrm{PhD}$ thesis, University of Pennsylvania.

Hoh JFY, Yeoh OH (1979) Rabbit skeletal myosin isoenzymes from foetal, fast twitch and slow twitch muscles. Nature 280:321-323.

Iscoe S, Dankoff J, Migicovsky R, Polosa C (1976) Recruitment and discharge frequency of phrenic motoneurones during inspiration. Respir Physiol 26:113-128.

Keens TC, Bryan H, Levison H, Ianuzzo CD (1978) Developmental patterns of muscle fiber types in human ventilatory muscles. J Appl Physiol 44:909-913.

Kelly AM, Rosser BWC, Rubinstcin NA, Nemeth PM (1990) Biochemical properties of the diaphragm during development of respiratory function in the rat. In: The dynamic state of muscle (Pette D, ed), pp 181-192. Berlin: DeGruyer.

LaFramboise WA, Daood MJ, Guthrie RD, Butler-Browne GS, Whalen RG, Ontell M (1990) Myosin isoforms in neonatal rat extensor digitorum longus, diaphragm, and soleus muscles. Am J Physiol 259: L116-L122.

Lowry CV, Kimmey IS, Felder S, Chi MM-Y, Kaiser K, Passoneau P, Kirk KA, Lowry OH (1978) Enzyme patterns in single human muscle fibers. J Biol Chem 253:8269-8277.

Lyons GE, Haselgrove J, Kelly AM, Rubinstein NA (1983) Myosin transitions in developing fast and slow muscles of the rat hindlimb. Differentiation 25:168-175.

Mahdavi V, Izumo S, Nadal-Ginard B (1987) Developmental and hormone regulation of sarcomeric myosin heavy chain gene family. Circ Res 60:804-814.

Maltin CA, Duncan L, Wilson AB (1985) Rat diaphragm: changes in muscle fiber type frequency with age. Muscle Nerve 8:211-216.

Maniatis T, Firtsch EF, Sambrook J (1982) Molecular cloning: a laboratory manual, pp 191-193. Cold Spring Harbor, NY: Cold Spring Harbor Laboratory Press.

Maxam AM, Gilbert W (1980) Sequencing end labeled DNA with base-specific chemical cleavage. Meth Enzymol 65:499-560.

Maxwell LC, McCarter RJM, Kuehl TJ, Robotham JL (1983) Development of histochemical and functional properties of baboon respiratory muscles. J Appl Physiol 54:551-561.

Mortola JP (1984) Breathing pattern in newborns. J Appl Physiol 56: 1533-1540.

Nadal-Ginard B, Medford RM, Nynyen HT, Periasamy M, Wydro RM, Horning D, Gubits R, Garfinkel LI, Wieczorek DF, Bekesi E, Mahdavi V (1982) Structure and regulation of a mammalian sarcomeric myosin heavy-chain gene. In: Muscle development: molecular and cel- 
lular control (Pearson ML, Epstein HF, eds), pp 143-168. Cold Spring Harbor, NY: Cold Spring Harbor Press.

Narusawa M, Fitzsimons R, Izumo S, Nadal-Ginard B, Rubinstein NA Kelly AM (1987) Slow myosin in developing rat skeletal muscle. J Cell Biol 104:447-459.

Nemeth PM, Turk WR (1984) Biochemistry of rat single muscle fibers in newly assembled motor units following nerve crush. J Physiol (Lond) 355:547-555.

Nemeth PM, Solanki L, Gordon DA, Hamm TM, Reinking RM, Stuart DG (1986) Uniformity of metabolic enzymes within individual motor units. J Neurosci 6:842-898.

Nemeth PM, Norris BJ, Solanki L, Kelly AM (1989) Metabolic specialization in fast and slow muscle fibers of the developing rat. $J$ Neurosci 9:2336-2343.

Okubo S, Mortola J (1988) Long-term respiratory effects of neonatal hypoxia in the rat. J Appl Physiol 64:952-958.

Page AM, Krebs AH, Williams DH (1971) Activities of enzymes of ketone body utilization in brain and other tissues of suckling rats. Biochem J 121:49-53.

Periasamy M, Wieczorek DF, Nadal-Ginard B (1984) Characterization of a developmentally regulated perinatal myosin heavy chain gene expressed in skeletal muscle. J Biol Chem 259:13573-13578.

Reiser PJ, Kasper CE, Greaser ML, Moss RL (1988) Functional significance of myosin transitions in single fibers in the developing soleus muscle. Am J Physiol 254:C605-C613.

Reiser PJ, Moss RL, Guilian GG, Greaser ML (1985) Shortening velocity and myosin heavy chains of developing rabbit muscle fibers. J Biol Chem 260:14403-14405.

Kosenthal J, Taraskevich PS (1977) Reduction of multiaxonal innervation at the neuromuscular junction of the rat during development. J Physiol (Lond) 270:299-310.

Rosser BWC, Choksi RM, Kelly AM, Nemeth PM (1988) Early metabolic differentiation in the diaphragm. Soc Neurosci Abstr 14:1147.
Rubinstein N, Kelly AM (1981) Development of muscle fiber specialization in the rat hindlimb. J Cell Biol 90:128-144.

Russell SD, Cambon N, Nadal-Ginard B, Whalen RG (1988) Thyroid hormone induces a nerve-independent precocious expression of fast myosin heavy chain mRNA in rat hindlimb skeletal muscle. J Biol Chem 263:6370-6374.

Schiaffino S, Saggin L, Viel A, Ausoni S, Sartore S, Gorza L (1986) Muscle fiber types identified by monoclonal antibodies to myosin heavy chains. In: Biochemical aspects of physical exercise (Benji $G$, Packer L, Siliprandi N, eds), pp 27-34. Amsterdam: Elsevier.

Schiaffino S, Gorza L, Sartore S, Saggin L, Ausoni S, Vianello N, Gunderson $\mathrm{K}$, Lomo $\mathrm{T}$ (1989) Threc myosin heavy isoforms in type II skeletal muscle fibers. J Musc Res Cell Motil 10:197-205.

Sieck GC (1988) Diaphragm muscle: structural and functional organization. Clin Chest Med 9:195.

Sieck GC, Blanco CD (1987) Changes in diaphragm fiber size and oxidation capacity during postnatal development. Am Rev Respir Dis 135:A332.

Sieck GC, Fournier M (1989) Diaphragm motor unit recruitment during ventilatory and non-ventilatory behaviors. J Appl Physiol 66: 2539-2545.

Smith D, Green H, Thomson J, Sharratt M (1988) Oxidative potential in developing rat diaphragm, EDL, and soleus muscle fibers. Am J Physiol 254:C661-C668.

Termin A, Staron RS, Pette D (1989) Myosin heavy chain isoforms in histochemically defined fiber types of rat muscle. Histochemistry 92:453-457.

Weydert A, Barton P, Harris AJ, Pinset C, Buckingham M (1987) Developmental pattern of mouse skeletal myosin heavy chain gene transcripts in vivo and in vitro. Cell 49:121-129.

Whalen RG, Sell SM, Butler-Browne G, Schwartz K, Bouveret P, PinsetHarstrom T (1981) Three myosin heavy chain isoenzymes appear sequentially in rat muscle development. Nature 292:805-809. 